\title{
THE DEVELOPMENT OF A COMPUTER DRIVEN JIGSAW
}

\author{
A.J. Lubbe and H. Raath \\ Department of Industrial and Systems Engineering \\ University of Pretoria \\ jlubbe@postino.up.ac.za
}

\begin{abstract}
With a jigsaw, sharp inside corners can only be sawn out if the blade of the jigsaw is lifted out of the material and the corner is approached from two different sides. For the blade to be able to re-enter the material no material must be present at the entry point.

The most important feature of an automated jigsaw is that it should be able to round off inside corners on a contour and automatically return to these corners to remove material left between the round off and the contour.

With this development project an automated jigsaw machine was designed, built and tested. Emphasis fell on the development of software that enables one to draw contours that need to be sawn out, change these contours into cutter paths for the jigsaw and transform the cutter paths into digital format necessary to control the jigsaw machine via the parallel port of a personal computer.
\end{abstract}

\section{OPSOMMING}

'n Figuursaag kan slegs skerp binnehoeke saag as die lem uit die materiaal uitgelig word en die hoek van twee kante af gesaag word. Waar die lem weer in die materiaal ingaan, mag geen materiaal aanwesig wees nie.

Die belangrikste eienskap van 'n ge-outomatiseerde figuursaag is dat kontoere so gesaag moet word dat binnehoeke afgerond kan word en die materiaal tussen die afronding en die gewensde kontoer outomaties verwyder moet word.

Met hierdie ontwikkelingsprojek, is 'n ge-outomatiseerde figuursaag ontwerp, gebou en getoets. Die klem van die projek val op die ontwikkeling van sagteware waarmee kontoere wat uitgesaag moet word, geteken kan word, omgeskakel kan word in 'n snyerpad vir die saaglem en gebruik kan word vir digitale beheer van die saagmasjien deur gebruik te maak van die parallelpoort van ' $n$ persoonlike rekenaar. 


\section{INTRODUCTION}

Manufacturing machines with the ability to follow a computer described cutting path are well known and are commonly called computer numerically controlled [1] machines (CNC). They have the ability to take into account the radius of the cutter (where the cutter can be physical, a beam or a flame) so that the side of the cutter can follow the required contour.

For a jigsaw to cut along a predetermined contour there are two main differences from normal CNC machines. Firstly, the blade of the cutter can only cut in the direction of the cutting edge whereas, vertical cutters such as slot mills, laser beams, flame cutters, etc., can cut in any direction on a horizontal plane. Secondly, a jigsaw cannot cut sharp corners because there is always a minimum turning circle required for the jigsaw blade to change direction of cut.

Computer aided design software (CAD) can be used to describe the cutter path for a jigsaw cutter but it would be required from the programmer to draw, for every sharp corner, a turning circle. Furthermore, it would be required that the programmer also describe new contours for each corner to remove material that cannot be removed during the initial cut because of the turning circle. Because of the abovementioned restrictions, it was decided to develop a unique, but simple $\mathrm{CAD}$ system that can draw the turning circles automatically, save the areas, for instance on an inside sharp corner between the turning circle and the required contour, that are impossible to cut and automatically add the motions needed to clear out the sharp corners after the initial cut. This software is called Jigsaw Designer.

Software was developed to control the motion of the jigsaw machine, while following the contour developed with Jigsaw Designer, in such a way that the orientation of the blade is always so that movement can only take place in the direction of the cutting edge of the blade. This software is called Jigsaw Cutter.

\section{TURNING CIRCLES}

Most CNC machines can only cut circles and straight lines [1]. To cut, for example, a contour like a parabola, the contour must be broken down into small straight lines. The shorter the successive lines, the more accurate the original contour can be approximated. Jigsaw Designer also uses only lines and circles to sketch all contours.

The web of a jigsaw blade restricts the blade to a minimum cutting radius. This minimum turning radius can be defined as the smallest radius that allows the cutting edge of the blade to follow a contour without the rear end of the blade, damaging the contour. This minimum cutting radius is a function of the length of the web of the blade and the programmer must specify this radius in Jigsaw Designer.

Turning circles must be generated at the intersection of two lines, two circles and at the intersection of a line and a circle. Depending on whether the blade is to cut the inside or the outside of a closed contour, different cutting circles need to be generated. Cutting on the inside means that the hole is the final product and cutting on the outside means that the piece of material falling out is the final product. 
Figure 1 shows two typical turning circles generated by Jigsaw Designer at the intersection of a line and a circle. The left contour shows the turning circle when the blade is to cut the outside of the contour while the contour on the right shows the turning circle for an inside cut. It should be noted that the sharp corner on the outside could be cut when it is possible for the blade to turn in the turning circle. For the inside contour, some material is left between the turning circle and the contour and the cutter must return to such a corner and approach the corner from two sides in order to remove all the material.

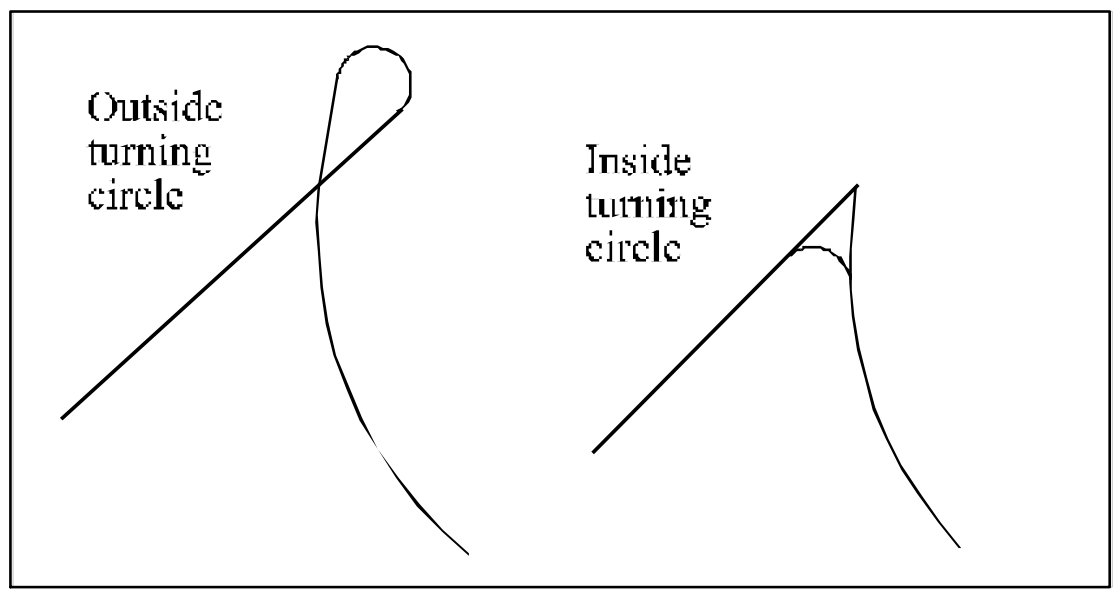

Figure 1: Typical Turning circles

Once all the segments of a contour have been selected in the order in which they are to be cut, Jigsaw Designer generates all the turning circles on screen and the programmer has to select the appropriate inside or outside turning circles.

\subsection{Turning circles between two intersecting straight lines}

Figure 2 shows the turning circles, for an inside cut and for an outside cut, needed when two lines intersect. The arrowheads show direction of cut, $\mathbf{r}$ is the minimum turning radius, $\mathbf{p}$ and $\mathbf{q}$ are the centre points of the inside and outside turning circles respectively, ? is the angle of direction change and $\mathbf{a}$ is the distance from intersection to the perpendicular touch point of the turning circle and the line.

The length a can be computed from:

$$
\mathrm{a}=\mathrm{r} \tan (? / 2),
$$

where? is always positive.

With reference to Figure 2, points $\mathbf{p}$ and $\mathbf{q}$ can respectively be found by constructing the appropriate circle with radius $\mathbf{r}$ that is perpendicular to the straight lines at a distance $\mathbf{a}$ from the intersecting point of the two lines. 


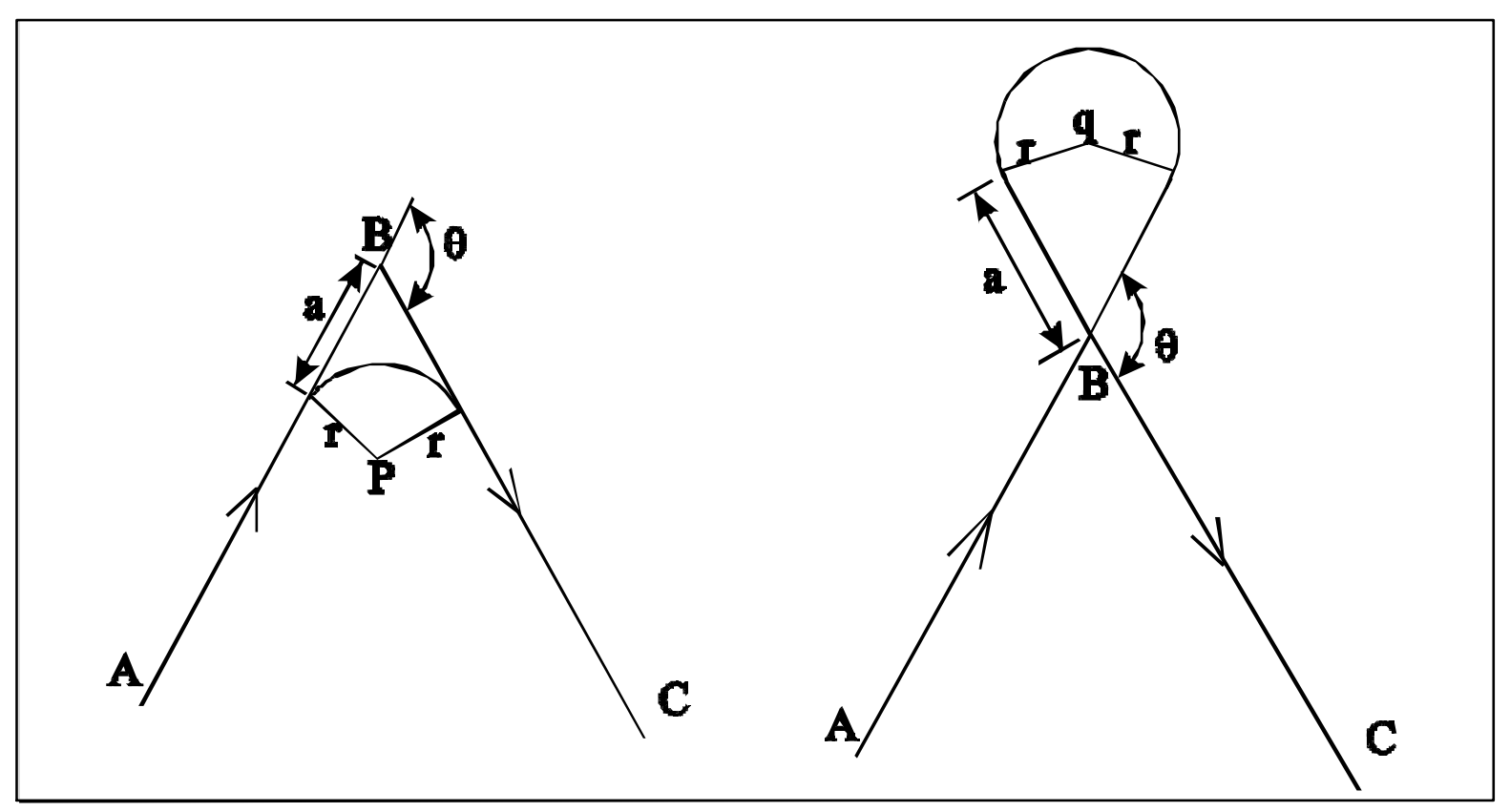

Figure 2: Rounding off between two intersecting lines

\subsection{Turning circles between two intersecting circles}

Figure 3 shows the four possible inside and outside turning circles that can arise between two intersecting circles.

The centre point of each one of the two intersecting circles is $\mathbf{m}_{\mathbf{1}}$ and $\mathbf{m}_{\mathbf{2}}$ respectively. $\mathbf{R}_{\mathbf{1}}$ is always the radius of the approaching circle and $\mathbf{R}_{\mathbf{2}}$ is the radius of the leaving circle. The turning circle for the outside circles is constructed by extending the circles at the intersecting point with tangent straight lines and then fit the circle in the same way as with two intersecting straight lines. Again ? is the angle of direction change, measured from the approach extension line to the leaving extension line, with positive sign when the direction is anticlockwise.

The centre points of the inside turning circles can be found with a search procedure. Two circles are constructed with centre points at $\mathbf{m}_{\mathbf{1}}$ and $\mathbf{m}_{\mathbf{2}}$ respectively. The radii of the circles are determined as shown in Figure 3, governed by the following rules.

1. If direction of rotation (clockwise or counter clockwise) of circles $R_{1}$ and $R_{2}$ is the same and ? is negative, then the radius of the first construction circle is R-r and the radius of the second construction circle is $\mathrm{R}_{2}-\mathbf{r}$.

2. If direction of rotation of circles $R_{1}$ and $R_{2}$ is the same and ? is positive, then the radius of the first construction circle is $\mathrm{R}_{1}+\mathbf{r}$ and the radius of the second construction circle is $\mathrm{R}_{2}+\mathbf{r}$.

3. If direction of rotation of circles $\mathrm{R}_{\mathrm{Y}}$ and $\mathrm{R}_{\mathbf{2}}$ is different and ? is negative, then the radius of the first construction circle is $R_{1}-\mathbf{r}$ and the radius of the second construction circle is $R_{2}+\mathbf{r}$.

4. If direction of rotation of circles $\mathrm{R}_{\mathrm{R}}$ and $\mathrm{R}_{2}$ is different and ? is positive, then the radius of the first construction circle is $R_{1}+\mathbf{r}$ and the radius of the second construction circle is $R_{2}-\mathbf{r}$. 


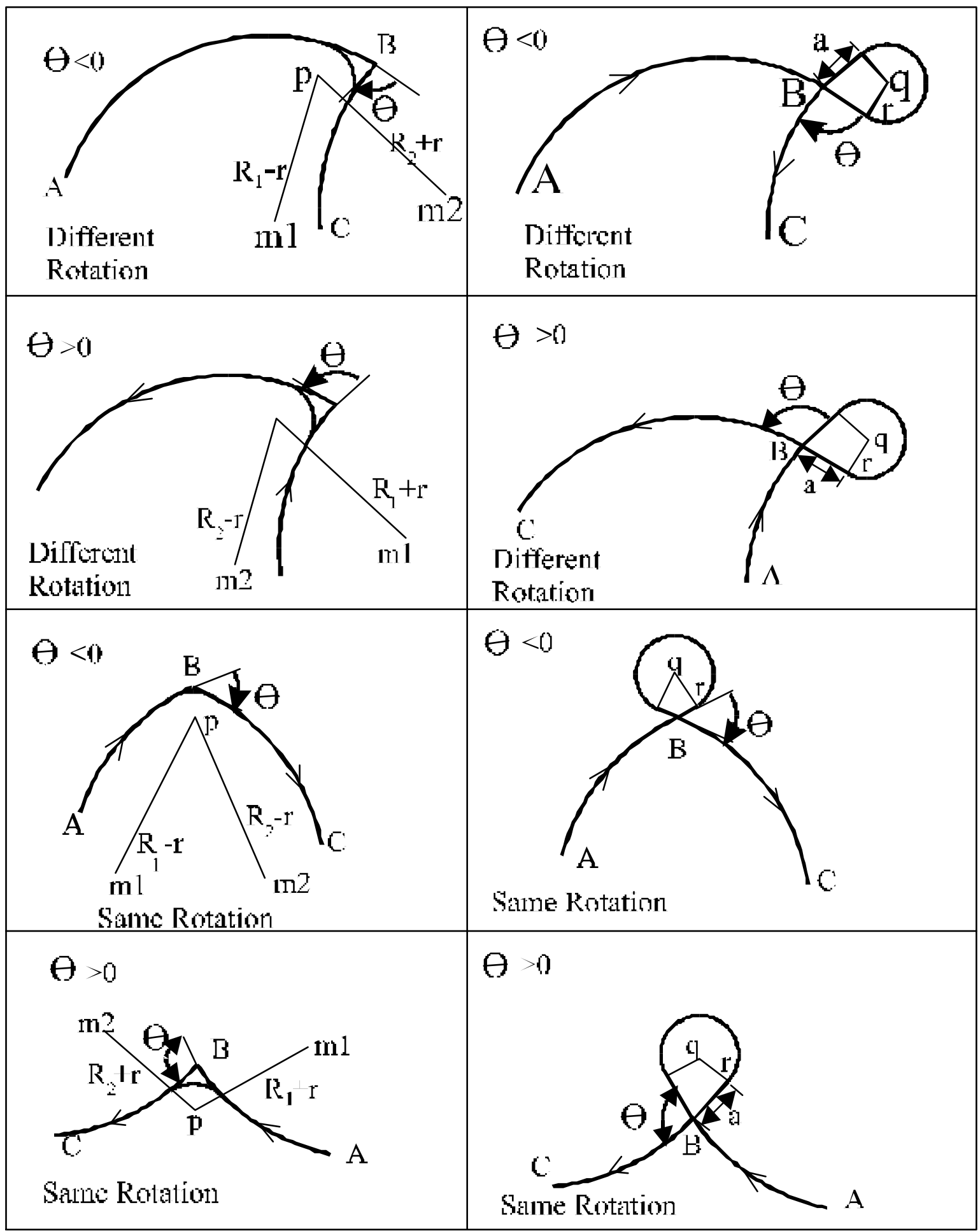

Figure 3: Rounding off between two intersecting circles

The intersection points of these two construction circles can be found geometrically, but by using a search procedure to determine the intersection point, the mathematical expression of the formulas is avoided. Figure 4 shows schematically the operation of the search procedure. 

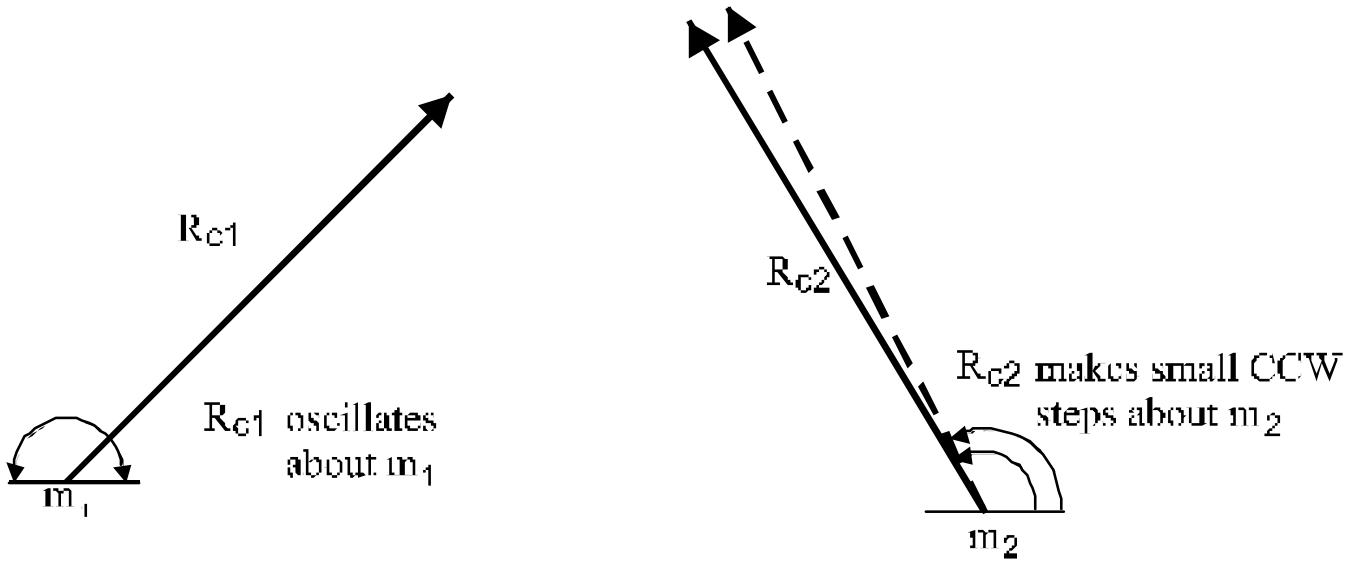

Figure 4: Schematic operation of the Search Procedure

Let $\mathbf{m}_{1}$ and $\mathbf{m}_{\mathbf{2}}$ be the centre points of the two construction circles with radii $R_{c 1}$ and $R_{c 2}$ respectively. $R_{c 1}$ oscillates through $180^{\circ}$ about $\mathbf{m}_{1}$, while $R_{c 2}$ is forced to rotate in small steps about $\mathbf{m}_{2}$. When the two lines (with lengths $\mathrm{R}_{\mathrm{c} 1}$ and $\mathrm{R}_{\mathrm{c} 2}$ respectively), intersect, the intersection point indicates the centre point of the turning circle.

\subsection{Turning circles between a circle and an intersecting line}

Figure 5 shows four possible turning circles where the approach is along a straight line and leaving the intersection is with a circle. Because of the similarity in mathematical approach with the abovementioned circles, the four cases where the approach is along the circle, are not shown.

The outside turning circles are treated in the same way as before, where a line tangent to the specified circle is drawn at the intersection point and the turning circle is fitted between two intersecting lines. The process of finding the centre points of the turning circles for these cases are very similar to those in the previous section. The rules for specifying the radius of the construction circles for the different intersecting circles can be determined from Figure 5 where the centres $\mathbf{p}$ and $\mathbf{q}$ with radius $\mathbf{r}$ refer to the turning circles.

1. If the circle is clockwise and ? is positive, then the radius of the construction circle is $\mathrm{R}_{2}+\mathbf{r}$.

2. If the circle is clockwise and ? is negative, then the radius of the construction circle is $\mathrm{R}_{2}-\mathbf{r}$.

3. If the circle is counter clockwise and ? is positive, then the radius of the construction circle is $\mathrm{R}_{2}-\mathbf{r}$.

4. If the circle is counter clockwise and ? is negative, then the radius of the construction circle is $\mathrm{R}_{2}+\mathbf{r}$. 


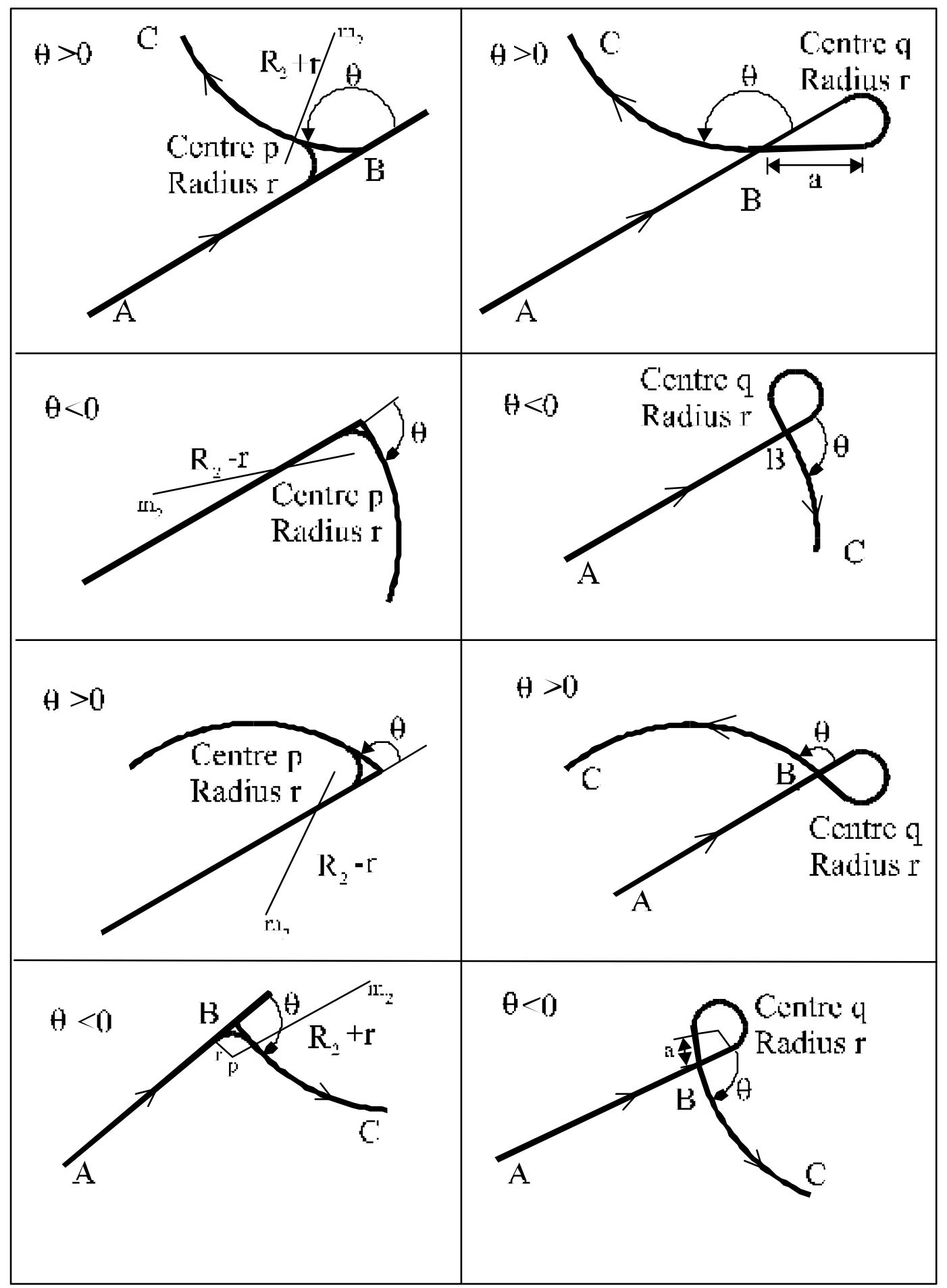

Figure 5: Rounding off between straight line and circle

A parallel line can be drawn at a distance $\mathbf{r}$ from the intersecting line, and the point where the line from $\mathbf{m}_{2}$ (length $\mathrm{R}_{\mathrm{c} 2}$ ) intersects the parallel line, the centre of the turning circle is located.

The turning circles for the four cases where the approach is along the circle, can be found in a similar way. 


\subsection{Application of turning circles}

In Figure 6, the top left drawing shows a pattern that needs to be cut on the outside and the top right drawing shows a pattern to be cut on the inside. The two bottom drawings show all the turning circles generated by Jigsaw Designer. From Figure 6 it can be seen that, for inside and outside contours, it is possible to have excess material left that must be removed after completion of the initial contour cut.
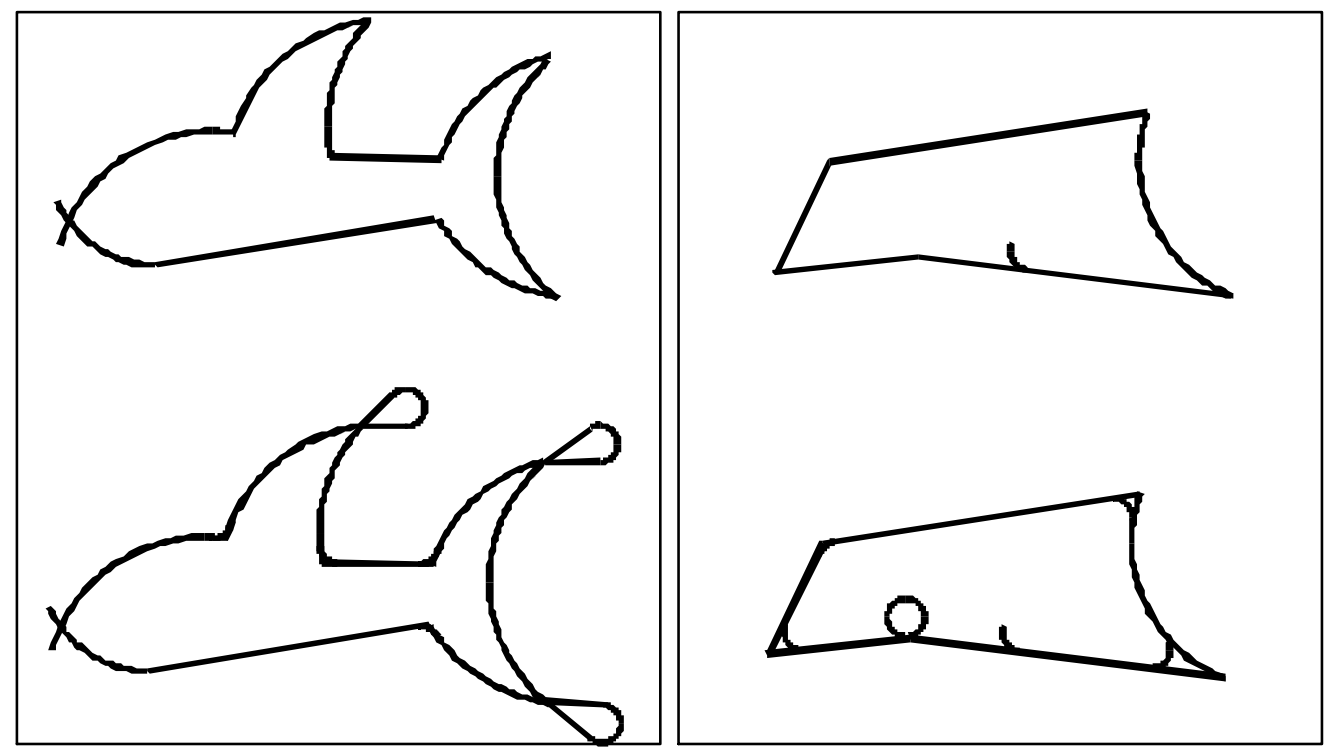

Figure 6: Turning circles generated by Jigsaw Designer

There are instances where it is physically impossible to cut contours (see Figure 7) because it is impossible to fit in turning circles between the two contours.

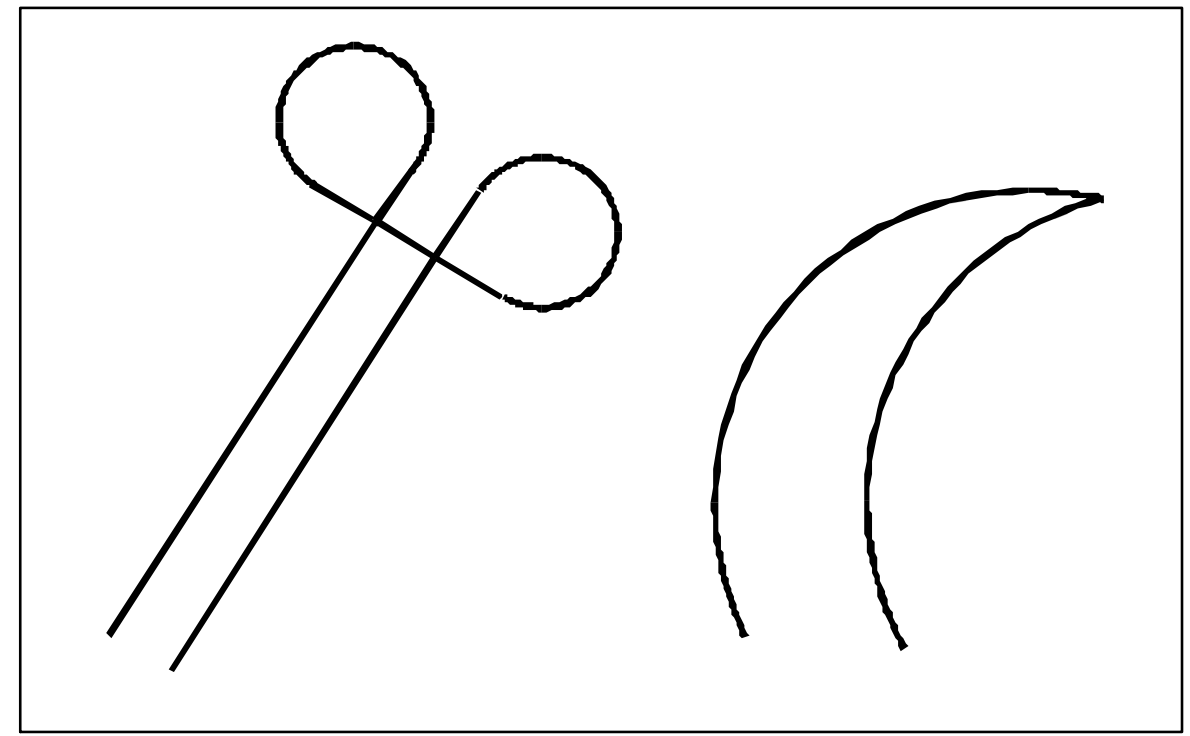

Figure 7: Impossible cuts 
One such a case arises when two parallel lines are so close to one another that it is impossible to fit a turning circle between the lines and only outside turning circles can be generated as shown. In the second example two intersecting circles form a very sharp corner and even the outside turning circle will be very far away from the intersection point. In such cases Jigsaw Designer tries to fit turning circles, but if it is impossible, wrong turning circles will be generated and the programmer can immediately see the result and can then either change the contour or remove the specific impossible contour.

\section{SPECIAL FEATURES OF JIGSAW DESIGNER}

\subsection{Entry Holes}

For every contour that needs to be cut, an entry hole for the jigsaw, with the same diameter as a turning circle, must be drilled. The programmer specifies these points and Jigsaw Designer ascertains that all contours start at the entry holes. Jigsaw Designer automatically draws the entry holes.

\subsection{Preventing material fall out}

When a closed contour is cut, the material on the inside of the contour will drop out if it is not supported from underneath. To facilitate the support, Jigsaw Designer makes provision for the closed contour to be broken up in different segments with a small piece of material in between each segment cut. These small pieces of material can be removed by the saw or left in place so that the operator can press out the centrepiece.

\subsection{Removal of corner material}

After generating the corner circles, Jigsaw Designer automatically stores in memory [2] those pieces of the contour that need to be cut after the initial contour cut. During the initial contour cut the saw follows the contour until it reaches an inside corner and continues until the intersection point is reached. It then reverses back along the contour until it reaches the tangent point at the turning circle and then cut forwards along the turning circle. After completion of the initial contour cut the saw returns to each inside corner in such a way that the blade goes into the material at the end point of each corner circle with the correct orientation of the blade. It then cuts along the contour up to the intersection point. At the intersection point the saw retracts and then moves to the end point of the next corner circle. This is repeated until all corner material has been removed in this reverse order.

Because the Z-movement was not automated for the prototype machine, the vertical movement is performed manually, however, the computer gives a signal when Z-movement needs to be performed.

\section{HARDWARE DESIGN}

In concept it is necessary to mount a normal electrical jigsaw on a frame that can move the saw in the X- and Y-plane. It is further necessary to attach the saw in such a way that rotation of the jigsaw will always be about the cutting edge of the jigsaw blade. Vertical or Zmovement needs a frame to hold the material to be cut and for the prototype it was decided to 
make this movement manual.

\subsection{X-Y-Movement}

Horizontal movement of the jigsaw was achieved by building a rigid frame fitted with gliding rods in the $\mathrm{X}$ and $\mathrm{Y}$ directions with the necessary drive screws.

\subsection{Driver Mechanism}

Straight-line movements in the $\mathrm{X}$ - and Y-directions were achieved by connecting a step motor to the X-lead screw, which in turn, could move a sliding block in the X-direction. A similar lead screw and step motor can move the Y-axis perpendicular to the $\mathrm{X}$-axis but underneath it. Sliding shafts mounted in sliding bearings forces the sliding blocks to move linearly.

Figure 8 shows the jigsaw mounted in position at the end of the rotational Z-Axis with the frame and motors for horizontal movement.

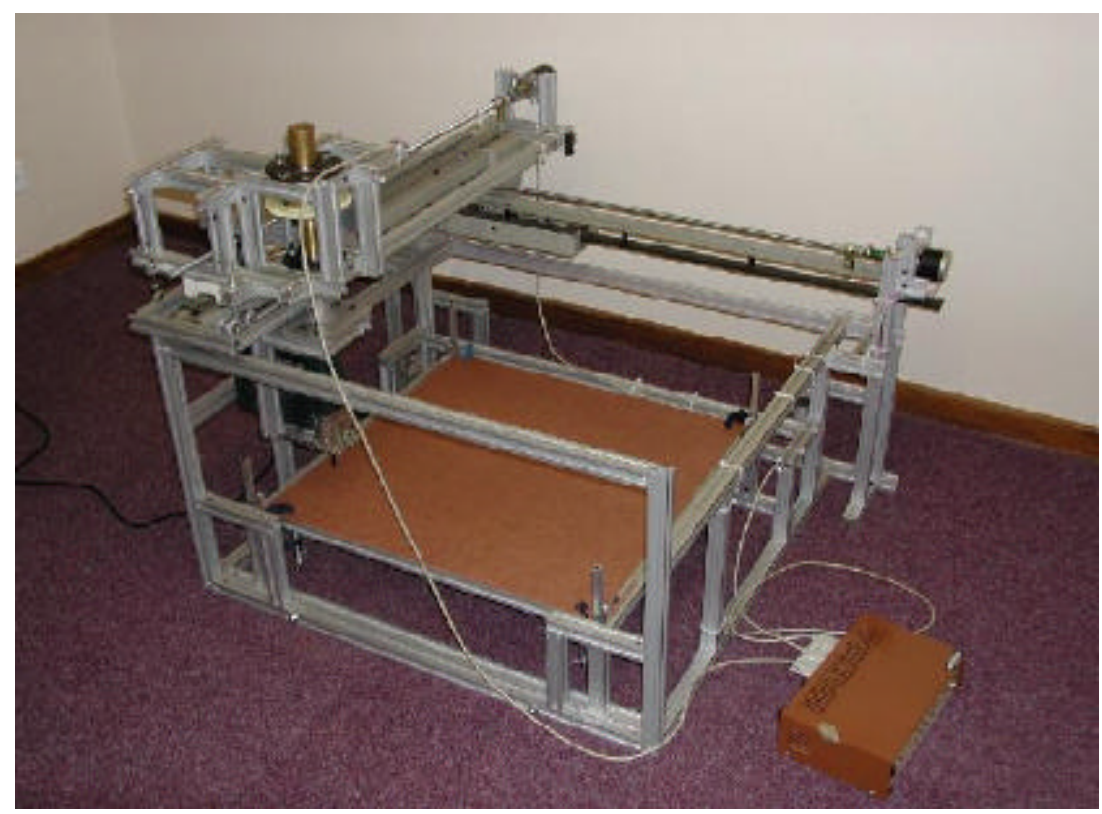

Figure 8: Assembled Jigsaw machine

\section{JIGSAW CUTTER}

Rotation of the different step motors for moving the machine in the $\mathrm{X}-\mathrm{Y}$ directions and for rotation of the jigsaw are accomplished by sending digital signals [3,4] through the parallel port [5] of a personal computer (PC) to the drivers [6] of the step motors. The control software, called Jigsaw Cutter, was written in Borland Turbo Pascal 7.0. [2] After completion of a design with Jigsaw Designer, Jigsaw Cutter is automatically called so that the user is unaware that two different software programmes are utilized.

\subsection{Linear Interpolation}

When cutting a straight line at an angle (excluding 45 degrees) the $\mathrm{X}$ and $\mathrm{Y}$ - motors must run 
at different speeds. The ratio of the speeds is directly proportional to the distance that each motor must move the slide linearly.

The speed of a step motor is controlled by the number of drive pulses the driver receives from the PC in a specific time span. An algorithm was developed that would precisely control the ratio of the speeds of the motors while taking into account the gear ratio of each motor drive.

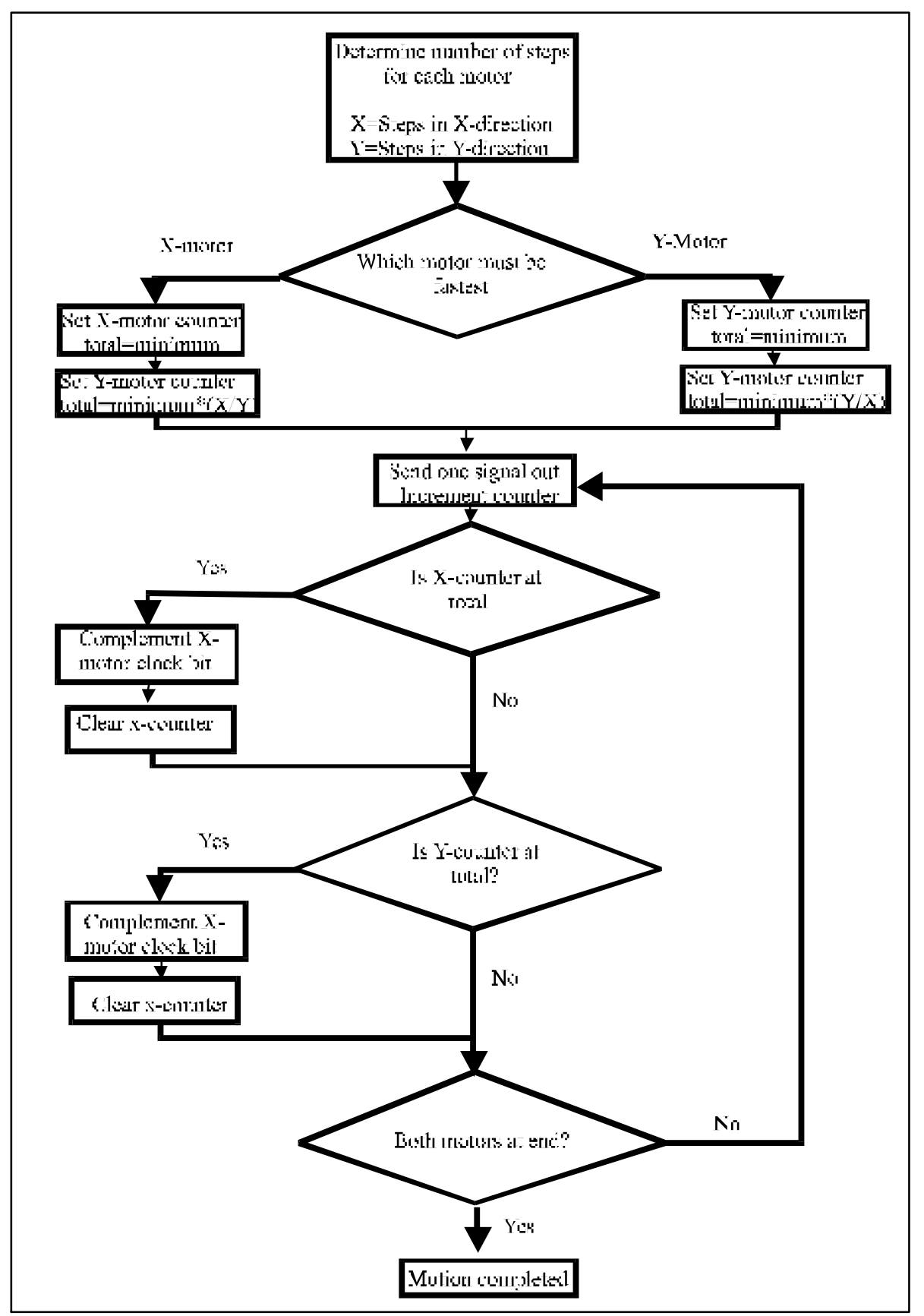

Figure 9: Block diagram of linear interpolation algorithm

In the algorithm (see Figure 9) there is a counter for each of the two axes. At every clock pulse, the counters are incremented until one counter reaches that variable that indicates that 
one signal can be sent out to make that specific motor turn one step. In this way it is possible to force the motors to run at different speeds, but to reach the end point simultaneously.

\subsection{Circular Interpolation}

Circular interpolation is achieved in a similar way by breaking the circle segment into very small straight lines. The shorter the lengths of the straight lines the more accurate the interpolation will be. The lengths of the straight lines were determined experimentally.

These small straight lines are interpolated with the same algorithm as the linear interpolator.

\subsection{Rotation of the vertical axis}

The jigsaw is mounted on the vertical Z-axis in such a way that rotation is always about the cutting edge of the jigsaw blade. For the prototype, the smallest rotation is $1 / 3$ of a degree.

At the start of each line segment Jigsaw Cutter determines the direction of cut in terms of a world co-ordinate system and orientates the Z-axis accordingly to ascertain that movement can only be in the direction of the cutting edge of the blade.

\subsection{Marking of entry holes}

Before commencing to cut the contour Jigsaw Cutter moves the cutter to each entry point individually where it dwells for a short while before moving on to the next entry point. This allows the operator to mark all the entry points so that they can be drilled prior to the contour cut. All entry holes must be drilled with the same radius as that of the turning circles.

\section{TEST RESULTS}

Jigsaw Designer was used extensively to test all types of awkward shapes and it was ascertained that all shapes, which can practically be cut correctly with a jigsaw, could be drawn and correctly fitted with turning circles. In all cases the excessive material between the inside turning circles and the contour was removed correctly.

Different people were requested to use Jigsaw Designer to design their own contours. It was found to be user friendly and the option to leave some material to prevent the material from falling out made application very versatile.

Jigsaw Cutter was first tested with a pencil in the position of the jigsaw blade to test for accuracy and repeatability. After various repeats the lines drawn with the pencil were sometimes wider than the width of the jigsaw blade. These inaccuracies could be caused by the flexibility of the frame.

Finally, the completed machine was tested on hardboard. Figure 10 shows two typical machined shapes. Orientation of the blade was done correctly as well as approaching of the contour to remove excessive material. The tests showed that the rapid speed, with the blade away from the material, is too slow. 


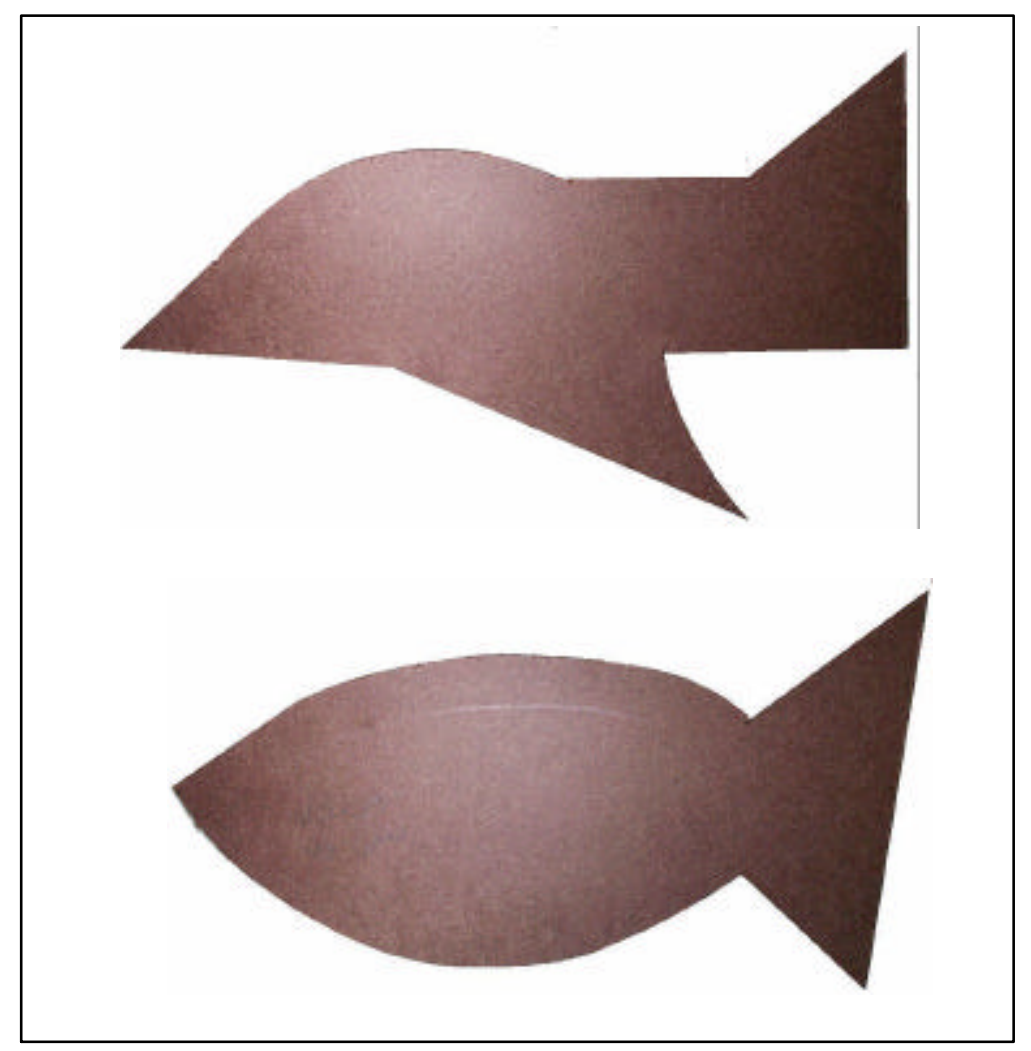

Figure 10: Cutting results

\section{CONCLUSIONS}

The objectives of this research project was to develop and test the software needed to draw contours for jigsaw cutting, transform the contours into cutting paths for a jigsaw and to control the jigsaw to cut the contours correctly and to remove corner material.

The transformation of the drawing into a cutter path for the jigsaw with its associated ability to remove corner material is unique. The patent attorneys D.M. Kisch did a worldwide search for similar products and in the absence of any, took out a provisional patent for this system.

On the mechanical side, many improvements are possible. The frame is not rigid enough, the rapid feed is too slow, entry holes must be drilled by hand and vertical movement of the jigsaw, in and out of the material, is not automated.

With this development project it has been demonstrated how mathematical functions can be applied to create cutting paths and how these cutting paths can be transformed into digital data that can be transferred through the parallel port of a personal computer to drive step motors through the necessary step motor drivers and control motion in a desired way. 


\section{REFERENCES}

[1] Groover M.P., 2001. CAD/CAM: Computer-Aided Design and Manufacturing, Prentice-Hall International Editions, New Jersey.

[2] Reisdorph K. 1998. Teach Yourself Borland Delphi 4 in 21 Days, Borland Press, USA.

[3] Gilmore CM. 2000. Microprocessors-Principles and Applications, $3^{\text {rd }}$ Edition, McGraw-Hill.

[4] Bergsman P. 1998, Controlling The World With Your PC, High Text Publications Inc., Solana Beach, California, USA.

[5] Lubbe, A.J. Die ontwikkeling van 'n opleidingsmikrobeheerder vir nie-elektroniese ingenieurs. S A Tydskrif vir Natuurwetenskap en Tegnologie, Vol 16, No. 3, 1997 pp 135-139.

[6] Lubbe, A.J. Die ontwikkeling van 'n prototipe borduurmasjien vanaf 'n huishoudelike naaimasjien. S A Tydskrif vir Natuurwetenskap en Tegnologie, Vol 18, No. 4, 1999 pp120-125 